\title{
El docente de lengua castellana: un profesional en busca de su identidad 192
}

\author{
Horacio Gutiérrez Ruskin \\ cubalibrechexxi@gmail.com \\ Carol Lucia Bernárdez \\ megaosita93@yahoo.com.mx \\ Estudiantes Universitarios
}

"Es necesario corregir la inferioridad

Que significa la falta de conocimiento"

Che

\section{Justificación de este escrito}

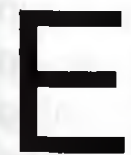
I documento de reforma a la Ley 30 fue la gota que derramó el vaso. ¿O será la copa? Da igual. Pero no fue el documento de la reforma en sí mismo, ni las declaraciones gubernamentales en boca ya sea de la honorable ministra de educación o del propio presidente Santos, o la malformada opinión de los medios masivos de comunicación, no. Tampoco fue el detonante el tan acostumbrado discurso mamerto de la comunidad educativa de la universidad pública que trae consigo paros ya sea totales o escalonados, destrucción de planta física y una buena dosis de piedra, marchas $y$ arengas, todo esto como actividad que caracteriza a los estudiantes que van a la universidad... pública ${ }^{193}$ Menos aún los cómodos discursos de los maestros o docentes universitarios que se regodean en su vida burguesa fruto en muchos casos del manejo del discurso académico acomodado y cuya actitud de compromiso no pasa de la figuración en Aspu, de un ocasional discurso retórico en ocasiones frente a estudiantes deslumbrados pero bobos, y en otras en los claustros de consejo de departamento, facultad y académico, en sus cocteles intelectuales llamados congresos de..., en sus acomodadas comisiones de estudio y en el reencauche de teorías elevadas y difusas que al final nadie entiende. ¡NO! Lo que nuestros lectores van a encontrar en este ensayo -pues es a ese género al que creemos haber llegado muy a pesar de las opiniones maquiavélicas y prepotentes de los profesores de literatura-es la presentación de un punto de vista de dos estudiantes que se han encontrado en medio

${ }^{192}$ Este articulo es el resultado del informe de práctica docente entregado en febrero de 2012.

${ }^{193}$ Quienes olvidan buenas ideas como las del Che: "O nosotros somos capaces de destruir con argumentos las ideas contrarias, o debemos dejar que se expresen. No es posible destruir ideas por la fuerza, porque esto bloquea cualquier desarrollo libre de la inteligencia." 
de un fuego cruzado entre las políticas estatales, los pseudodiscursos académicos que se reciben en las aulas de clase de la universidad, el discurso académico-científico de los artículos de investigación y los libros especializados, las preguntas de los padres de familia, las nuestras propias, las de los egresados, las de nuestros estudiantes en las prácticas docentes y de la comunidad en general sobre el papel del profesor de español en esta desequilibrada realidad colombiana. La tesis que queremos defender es que la imagen de identidad docente ofrecido en los programas de español y literatura - llamado también de lengua castellana de diferentes universidades colombianas, ha sido el resultado de una mezcolanza de contenidos que van desde los cursos de lingüistica, de literatura, de sicología, de semiótica, de análisis del discurso y de didáctica sin el mayor asomo de interrelación, autonomía y humanismo tan necesarios en este mundo globalizado. Queremos proponer además una reflexión sobre lo que a nuestro criterio debería ser el complemento de una organización curricular para lograr ser exitosa y productiva en la formación de profesores en el área de español.

Tenemos una deuda intelectual con varios autores que han presentado ideas revolucionarias en el área de la pedagogía, la literatura, la lingüística, la semiótica y cuyo contacto lastimosamente ha sido sólo a través de los libros y en ocasiones muy contadas, de las recomendaciones de buenos profesores que por fortuna todavía existen. El apoyo desinteresado de nuestras familias ha sido definitivo en esta reflexión. No podemos olvidar a nuestros estudiantes del Colegio Provincial San José, futuro de nuestro país y son ellos los que de manera silenciosa cuestionan nuestra labor docente. Queremos agradecer finalmente a la revista Paideia Surcolombiana, órgano de la Facultad de Educación de la Universidad Surcolombiana y en especial al asistente editorial profesor Miguel Ángel Mahecha el haber acogido este artículo que fue vetado en otras publicaciones tal vez por decir lo que pocos se atreven a decir pero que en el fondo todos saben.

\section{El Sistema Educativo Colombiano y la enseñanza del español}

Sólo haremos algunos comentarios sobre referentes puntuales en la planeación dirigida desde el Ministerio de Educación Nacional y la manera como se interpretan en las facultades de educación con respecto al papel de la lengua materna y la manera de enseñarse en la educación básica y media. En lo referente a la enseñanza del español en la universidad, se harán observaciones subjetivas desde nuestra propia experiencia como estudiantes, la mayor parte del tiempo pasivos y muy buenos realizadores de tareas escolares.

En las propias palabras del Ministerio, en el espíritu de los lineamientos hay espacio para la autonomía, la democracia, la creatividad, el pensamiento crítico: "Los lineamientos buscan fomentar el estudio de la fundamentación pedagógica de las disciplinas, el intercambio de experiencias en el contexto de los Proyectos Educativos Institucionales. Los mejores lineamientos serán aquellos que propicien la creatividad, el trabajo solidario en los microcentros o grupos de estudio, el incremento de la autonomía y fomenten en la escuela la investigación, la innovación y la mejor formación de los colombianos." (p. 3) Sin embargo nos preguntamos por qué no son visibles, al menos en nuestras facultades de educación, la fundamentación científica y pedagógica, la creatividad, el fomento de la autonomía cuando se está llevando a cabo la práctica pedagógica. Uno escucha un discurso en boca del profesor, pero dicho discurso no tiene la más mínima relación con lo que se llevará a cabo en la vida misma, en la práctica profesional. Los profesores universitarios, no se diferencian de los profesores de colegio e imponen su opinión sin una argumentación válida; sólo lo logran a 
través de su investidura de poder. Nos hemos preguntado cuáles son las asignaturas de un plan de estudios de la carrera de licenciatura en español que permiten cultivar "la calidad pedagógica en las aulas colombianas" además de ir creando y alimentando "la posición crítica y analítica del docente frente al trabajo del aula", cuando en realidad la práctica pedagógica del aula de clase universitaria deja mucho que desear. ¿Cuáles son "los espacios de reflexión permanente e investigación sobre la labor docente"? ¿Quién tiene la clave: la lingüística?, la literatura?, la sicología y la didáctica?, los seminarios de práctica docente?, las electivas? ¡Vaya uno a saber!...

Los autores de los documentos oficiales, el Ministerio de Educación mismo así como el ICFES, confirman que "la experiencia de la Renovación Curricular en nuestro país nos muestra que un avance hacia la calidad en las prácticas del lenguaje, y de las prácticas educativas en general, no se garantiza con contar con unos programas curriculares bien diseñados. Si la práctica pedagógica de los colectivos de docentes no está atravesada por el estudio permanente sobre los enfoques, procesos y competencias fundamentales que determinan el desarrollo integral de los estudiantes, difícilmente se avanzará hacia procesos de calidad. En este sentido, este documento es una invitación al análisis y al acercamiento a los planteamientos teóricos y pedagógicos que nutren la acción educativa." ¿Por qué esto no se discute en la Universidad? ¿Por qué no se discute en los colegios? Se supone que en estas dos instancias que son la base para una buena práctica pedagógica, se trabaja en la construcción no sólo de la imagen del profesor, sino en la consolidación de la imagen de los estudiantes quienes a la larga se están formando para ser ciudadanos de un país. En este aspecto, Carlos Gaviria y Jorge Robledo, del Polo Democrático han sido suficientemente claros.
En la preparación del documento oficial de lineamientos y también de los estándares, se utilizaron los contenidos académicos que hemos visto en la carrera: "Para la elaboración de este documento se tuvieron en cuenta planteamientos sobre desarrollo curricular, (didáctica, currículo y legislación educativa) conceptos de la lingüística del texto, (lingüística y análisis del discurso) de la psicología cognitiva, (psicología de la educación, psicología de los procesos mentales, pedagogía y currículo) de la pragmática, (lingüística, sociolingüística y pragmalingüística) de la semiótica (semiótica) y de la sociología del lenguaje; principalmente los trabajos desarrollados en estos campos en Colombia. Además, se tomaron como referencia tanto las conceptualizaciones como los resultados de las evaluaciones desarrolladas por el Sistema Nacional de Evaluación de la Educación SNE en el campo del lenguaje." Lo que va entre paréntesis es de nuestra autoría. Y preguntamos además: ¿Para qué sirven las materias de literatura si en el trabajo con los estándares y los lineamientos la base teórica no se sirve de la literatura o mejor de la teoría literaria?

Cuando llegan a nuestras manos libros tan impactantes como Pedagogía de la autonomía (Pablo Freire), Psicología y Pedagogía (Piaget), Los siete saberes necesarios para la educación del futuro (Edgar Morin), Elogio de la dificultad (Estanislao Zuleta), Hacia una pedagogía del conocimiento (Rafael Flórez Ochoa), Para una educación al alcance de los niños (García Márquez), El sentido de la pedagogía en la escuela (Agustin Nieto Caballero), Las fronteras de la Escuela (Antanas Mockus y otros), Diálogos sobre los grandes problemas del ser humano (Carlos Eduardo Vasco), etc., y confirmamos que dichos libros no hacen parte de la bibliografía básica (e incluso nos hubiese gustado que hubiera sido obligatoria) de los cursos sino que han sido desplazados por textos vacios (sin aplicación) aparentemente eruditos y poco entendibles como los textos de las 
asignaturas de literatura en especial la afrocolombiana, la indígena y regional, la literatura femenina sin dejar de lado las de las escuelas literarias, los de lingüística como los de van Dijk, los de Bernal Leongómez, los de Montes y Patiño Rosselli, los textos de semiótica como los de Eco, Barthes, Benveniste, Fontanille, Silva y Cuevas, y en didáctica que no se ve más que lectoescritura pues según esos docentes, lo esencial de la docencia es enseñar a leer, estamos cansados de Cassany, Emilia Ferreiro, Colomer, etc.

¿Cuál es el perfil y la identidad del profesor de Español en Colombia? Enseñar lectoescritura y hacer listas de libros para planes lectores sin saber cómo ni por qué ni para quién. Nos hemos llenado de información pero no sabemos qué hacer con ella. Un profesor pensionado de colegio nos preguntó por Luis Flórez y su legado. No supimos qué responderle. Cuando buscamos y encontramos lo que habia hecho Flórez para consolidar la identidad del profesor de español en Colombia ${ }^{194}$, confirmamos que nos habían privado de un valioso aporte. ¿Por qué? No lo sabemos.

\section{Lo que hemos visto}

La pregunta que en nuestras facultades de educación y en los espacios de las asignaturas ha estado ausente es: ¿Qué es lo que necesitan aprender nuestros estudiantes para que sean autónomos y felices? Los profesores de colegio $y$ universidad han mezclado imprudentemente el campo escolar y el campo investigativo disciplinar. Ellos han puesto al colegio y a los muchachos al servicio, o sería más exacto decir a la orden sumisa de teorias de investigadores de áreas específicas y diversas. Cuando se examina la génesis de las corrientes que han marcado por ejemplo la enseñanza de la literatura, de la lengua española, de la lengua inglesa, se constata que el punto de apoyo son las disciplinas como la lingüística y la teoría literaria. La didáctica es la disciplina que supuestamente asegura la transposición de los saberes de la universidad hacia el mundo del bachillerato, pero... Una de las misiones, nos parece y esa es la idea que queremos defender es que la misión de la didáctica (y eso tendría que mencionarse en los cursos de didáctica) ya sea de la literatura, de la lengua materna y de la lengua extranjera es de luchar contra la imposición, acumulación y derrame de teorías sin ningún tipo de aplicación. Encontrar juicios de crítica literaria o de crítica lingüística en textos desafortunados no contribuye ni al conocer ni al placer. Dicho en otros términos, el remedio que han propuesto los profesores para que los estudiantes lean no ha atacado el mal de raíz sino que han aumentado el desgano por la lectura, la escritura y la crítica autónoma. Hay que aportar respuestas y soluciones para que los profesores salven la enseñanza del español y la saquen de la crisis en que se encuentra.

Hay que darse cuenta de las relaciones que se establecen de manera natural entre la lingüística y la literatura. No se trata de imponer razones o de determinar la preeminencia de la una sobre la otra. La práctica pedagógica de los docentes se ha construido mezclando de manera irresponsable el componente estético, el estructuralista/gramatical y los enfoques pragmático-discursivos. Estamos enseñando, como lo afirma acertadamente William Díaz, literatura de los años sesenta y además manejando teorías que ya no se manejan, que ya no se utilizan. Se habla de estilistica atomística y orgánica. Y la lingüística no se salva tampoco, antes se solidariza con el aumento de errores y falacias. Los promotores del estructuralismo literario (Barthes, Greimas,

\footnotetext{
${ }^{194}$ Es un tesoro el libro del profesor Siervo Mora Monroy: La enseñanza del español en Colombia. Legado metodológico de Luis Flórez. Bogotá, Instituto Caro y Cuervo.
} 


\section{PAIOEIASurcolombiana 17}

Foucault, Lacan) sabian que habia que apoyarse en los logros teóricos de la lingüística para elaborar una verdadera ciencia del texto literario. $Y$ saber que en la práctica hay profesores que afirman en sus clases que el texto literario es lo máximo ignorando que lingüística (reina) mata literatura (peón) si asumimos la metáfora del ajedrez puesto que la lingüística es mucho más amplia en cuanto a las disciplinas que la componen, permitiéndole asi a los profesionales de las ciencias humanas, tener un amplio abanico de posibilidades para la investigación en pro del desarrollo intelectual. Cómo echamos de menos un taller sobre Bajtín quien tenia las cosas muy claras. En lugar de contentarse con acudir a teorías gramaticales para explicar el plano léxico, el semántico e incluso el fonético/fonológico, para apoyarse en sus explicaciones, crean pseudodiscursos de corte académico tratando de crear nociones ficticias como la competencia literaria, la hermenéutica literaria y la didáctica de la literatura que se resumen en la incoherente actividad descontextualizada de análisis de textos o en algunos casos de imágenes, que impiden el desarrollo de un aprendizaje real de la literatura. Incluso los estudios literarios que se consideran de un alto nivel de complejidad conceptual son los que más dolor de cabeza le producen a la inocente comunidad estudiantil: la narratología, la poética, la sociocrítica y el estudio del repertorio lexical (este último tema fue el contenido de nuestro curso de Poética) y aquellos que se construyen alrededor de la crítica, afirmando que la crítica literaria es condición obligatoria e indispensable para la elaboración de estudios complejos de análisis, una postura más que reprochable, pues cómo entonces se puede hablar de análisis literarios si todo el trabajo no queda sino a la sombra de otras voces con un mayor reconocimiento, $y$ entonces cuál es la originalidad del estudio, dónde está el valor investigativo que debe promover este tipo de trabajos, esto teniendo en cuenta los criterios para la formación profesional de un individuo.
Como si este tormento fuera poco, recientemente los profesores de literatura se han convertido en abanderados de los planes lectores en donde se busca demostrar una formulación con respaldo lógico-matemático: literatura es sí y sólo sí lectura y viceversa. ¿Cómo cuadra esta afirmación con lo que sugiere Anita Matute?: "No hay que darles a los alumnos la impresión de que la lectura es una obligación. Ése es uno de los grandes errores de la enseñanza hoy en día. La literatura no se enseña ni se aprende, se descubre." Para nosotros, profesores practicantes, la carrera de español no nos ayudó a descubrirla sino a ensombrecerla. La universidad no tiene espacio en las aulas pero de pronto sí en los muros y en los baños para pensamientos como los que presentamos:

Un curso de literatura no debería ser mucho más que una buena guía de lecturas. (Gabriel García Márquez)

Yo creo sentir la poesía y creo no haberla enseñado; no he enseñado el amor de tal texto, de tal otro: he enseñado a mis estudiantes a que quieran la literatura, a que vean en la literatura una forma de felicidad (Jorge Luis Borges)

Un buen poema es como una buena casa: con alguna instrucción previa, todos podemos comprobar si los materiales son de calidad, si están acertadamente utilizados, si la distribución es cómoda: pero otra cosa es que nos guste la idea de vivir ahi. (Francisco Rico).

Pasemos ahora al tema de las competencias. Hoy en día, como una noción común en el mundo educativo y profesional, la noción de competencia que se deriva de la lingüistica ( la oposición chomskyana de competencia/ actuación), designa generalmente el poder, para un sujeto cualquiera, de reunir conocimientos y saber-hacer con el fin de llevar a cabo una acción compleja. Las competencias se oponen a las divisiones que se establecen 
entre las disciplinas: la adquisición de un saber leer, un saber escribir, de un saber enseñar supera con creces los alcances de las materias de lingüística, de literatura, de didáctica, etc. Intuimos que las competencias fueron propuestas para ir más allá de la mera información y el recitar datos desperdigados sin ton ni son. Lo esperable en el corazón de la identidad docente es poder integrar los datos provistos por la observación de la vida real y su respectiva explicación desde el discurso pedagógico y el discurso científico. Lo que sucede en la realidad es otra cosa.

$Y$ pese a que es frecuente leer que el aprendizaje y la competencia es el desembarco de la empresa privada en la educación, en realidad el término competencia procede de la teoria lingüística de Chomsky no conocemos un lazo directo con el asunto capitalista. Con el desarrollo de las competencias se trata de formar a las personas no solo para que puedan participar en el mundo del trabajo sino para que sean capaces de desarrollar un proyecto personal de vida. La escuela debe formar personas con capacidad para aprender permanentemente: lectores inquietos, lectoras inquietas, ciudadanos participativos y solidarios, ciudadanas participativas y solidarias, padres implicados y madres implicadas, trabajadores innovadores y responsables y trabajadoras innovadoras y responsables.

\section{Nuestra postura}

Acaso es posible dar cuenta de cada una las acciones que se relacionan con las competencias? Si sabemos leer en español, eso quiere decir que somos buenos en la competencia lectora o en la escritora? Nos parece que no. Si sabemos hacer cuentas y recitar las tablas de multiplicar eso quiere decir que somos buenos en la competencia matemática? No. Y de qué forma un profesor puede evaluar dicha competencia si él no es más competente (casos se han visto) que su alumno? Ser profesor no garantiza eficacia, competencia. Ya lo decía B. Shaw: El que sabe hace el que no sabe enseña. A buen entendedor...Cuando se habla de las competencias en literatura, lingüistica y didáctica hay que mencionar algunas de sus particularidades las cuales se miden con los tan mencionados, poco usados y muy copiados estándares. Es lo que veremos en los siguientes tres elementos, gracias a algunas lecturas independientes de didáctica.

\section{La crisis del juicio científico}

Apropiarse de los conceptos básicos es deseable, esperable pero ha resultado imposible en nuestro medio. Si estamos siendo formados para ser profesores de español y literatura, deberíamos dar cuenta de lo que es lenguaje, lengua, competencia lingüística, competencia comunicativa, discurso, texto. De igual forma deberíamos saber qué cubre lo estético, lo bello, la constitución narrativa, la inspiración, la crítica, el mundo de sentidos, el símbolo, etc. Pero también qué es pedagogía, qué es didáctica, el enseñar, el amar y la visión humanista tal como la propone el profesor Ángel López: "Es necesario que las Humanidades recuperen el papel que tuvieron en los origenes de la civilización europea, que vuelvan a ser la conciencia de la actividad inteligente, la cual se aplica, por supuesto, al mundo natural y social, pero debe estar replanteándose continuamente las razones y los limites de su aplicabilidad."

De qué manera un enfoque por competencias le ayuda al profesor a evaluar la capacidad de los estudiantes para hacer una explicación gramatical, apreciar una obra literaria, diseñar un canon o proponer una estrategia pedagógica? Los profesores guardan silencio mientras que los practicantes se las tienen que ingeniar como sea complaciendo a alumnos, profesores titulares y directores de práctica todo para obtener una buena nota en el ejercicio de una mala práctica. Lo ideal de un Sistema Educativo es empezar a asumir que se trata de 


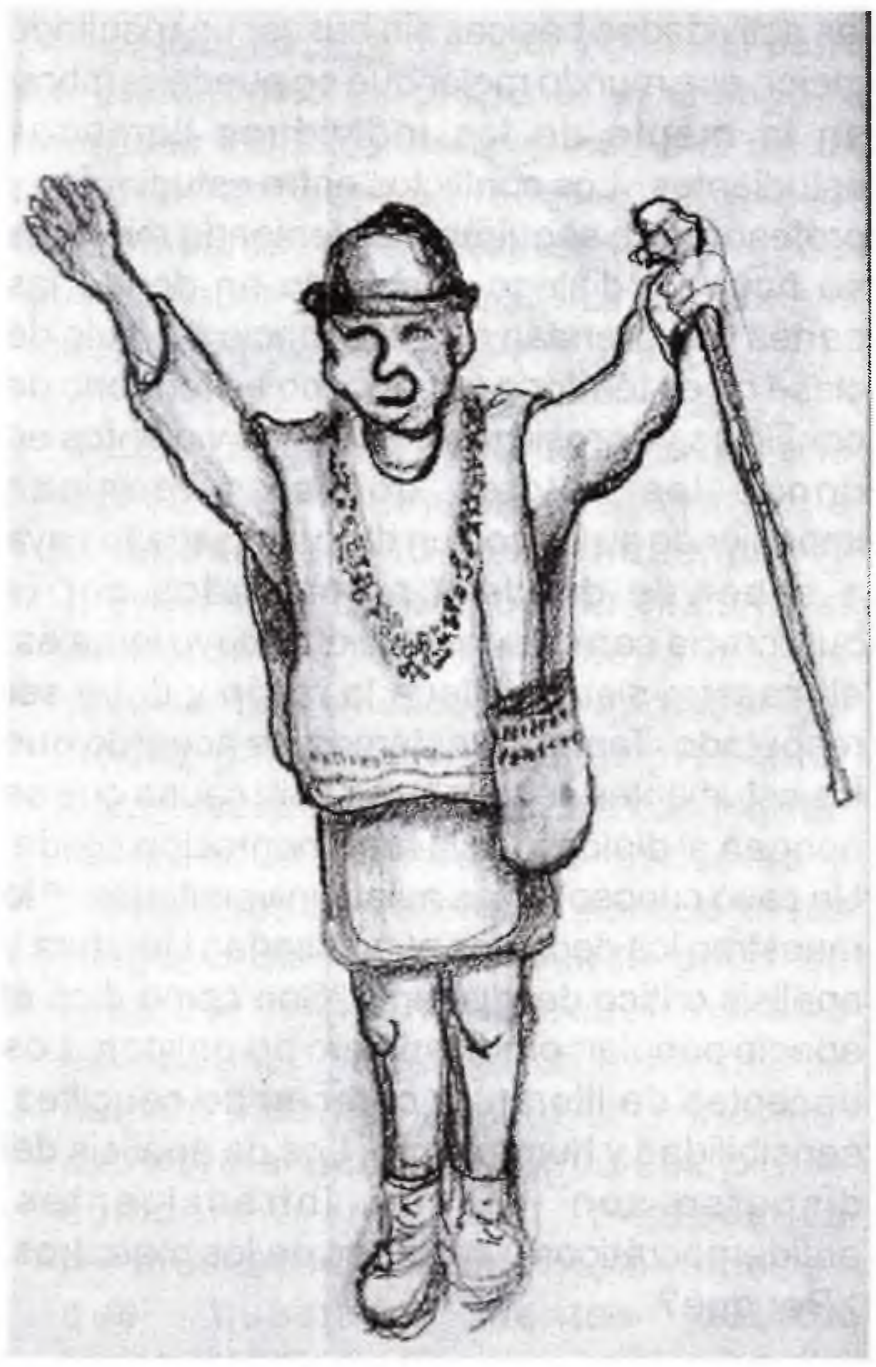

educar a ciudadanos y ciudadanas participativos y solidarios que sepan cómo actuar en un mundo globalizado y no reproducir en cadena individuos incapaces de afrontar los enormes retos de un mundo que va más allá de los libros, de las lecturas obligadas y repetitivas. Another brick in the wall! Acaso no han escuchado al maestro Pink Floyd?

We don't need no education

We don't need no thought control

No dark sarcasm in the classroom

Teachers leave them kids alone

Hey! Teachers! Leave them kids alone!

All in all it's just another brick in the wall.

All in all you're just another brick in the wall.

Vaya pregunta, ah! verdad que son profesores de español y literatura. El inglés es otro cuento y más peligroso aún. Al cambiar de herramienta conceptual por llamarlo de alguna forma, el profesor cambia de arma, no de interés.

2. La especificidad de las competencias escolares

Si tenemos en cuenta el informe de la UNESCO, recogido en el libro La educación encierra un tesoro (1996), afirmaba que hay cuatro pilares de la educación del futuro: aprender a conocer, aprender a hacer, aprender a vivir y aprender a ser. Hace parte de las competencias escolares? En teoría sí. Pero en la práctica no. Los miembros del MEN, del ICFES, de las Normales y las facultades de educación, perdieron la llave y no pueden disfrutar del tesoro. Nosotros tampoco. Si nos autoevaluamos, creemos que hemos sido estudiantes aceptables, hemos cumplido con responsabilidad nuestro rol de estudiantes universitarios de español y literatura. Hemos hecho las tareas pero cuando nos tocó llevar a cabo la práctica pedagógica, sentimos que éramos incompetentes en la labor docente. Nuestras competencias escolares que se reflejan en nuestras notas cuantitativas (los certificados de notas y el famoso promedio) mientras jugamos a representar al alumno son excelentes: cuatro cinco sobre cinco (4.5/5). Nuestras competencias escolares en la aplicación de un saber como profesores, como guías de alumnos es de cero punto cinco sobre cinco $(0.5 / 5)$. Las competencias escolares están compuestas por saberes específicos y su respectiva didactización. ¿Cómo integrar? Por supuesto que no sabemos y no podemos integrar porque nuestro respectivo plan de estudios universitario también está desconectado. Ni siquiera funcionan los prerrequisitos de asignaturas.

\section{La identidad profesional del profesor}

Esta es la parte en donde esperamos aportar argumentos para el debate de la calidad de la 
docencia y por ende del docente. La cuestión de la identidad profesional se plantea en términos $y$ en un contexto que ha venido cambiando con un ritmo acelerado, especialmente desde la última década del siglo $X X$. La evolución de la demanda social, la apertura de la Escuela al mundo exterior, las reformas ministeriales, la globalización económica y política sin mencionar la cultural (la aldea planetaria) son factores definitivos para definir la imagen compleja que debe tener un profesional de la enseñanza en nuestro medio. El profesor actual debe ser un individuo plural, multifacético, recursivo, competente y humano. Debe saber interpretar y adaptar una de las estrategias que el sistema ha diseñado para calificar y por tanto promediar las competencias de los profesionales que son los factores cuantitativos de la evaluación y de allí entonces que existan exámenes como las pruebas SABER, a nivel tanto de bachillerato (Saber 11) como universitario (Saber Pro). El resultado es entonces, la prueba de calidad de la institución en su desarrollo de la misión en cuanto a formadores de profesionales integrales capaces de desempeñarse en el campo de las humanidades, en cuanto a disciplinas se refiere.

En nuestros cursos de didáctica nos indicaron que 'profesar' significaba etimológicamente: 'declarar públicamente'. El profesor tiene una función de transmisor de un saber patrimonial y cultural que lo sitúa entre la tradición de lo que vive y la creación de posibilidades para entender eso que se vive. El profesor tiene un deber didáctico que consiste en organizar el corpus fijo, organizado y probado de cada saber transmitiéndolo de manera vulgarizadora pero sin traicionar el discurso original y logrando aplicaciones de dicho saber. Al fin de cuentas nos preguntamos cómo se podría definir o al menos calificar la identidad profesoral. La pregunta existe, se plantea porque sentimos que en la gran mayoría de los casos ser profesor de cualquier nivel de escolaridad resulta ser una profesión u oficio más en donde se llevan a cabo las actividades básicas sin buscar un resultado mejor: ese mundo mejor que se puede sembrar en la mente de los individuos Ilamados estudiantes. Los conflictos entre estudiantes y profesores se seguirán manteniendo mientras no haya un diálogo adecuado en donde las partes comprendan que el espacio del aula de clase no es territorio armado, no es territorio de conflictos y agresiones y espacios violentos en donde los actores docentes terminan imponiendo su ley con un discurso sacado vaya a saber de dónde y respaldados por la burocracia corrupta institucional cuyo lema es: el maestro siempre tiene la razón y debe ser respetado. Tampoco estamos de acuerdo que los estudiantes sean rebeldes sin causa que se oponen al diálogo y a la argumentación sólida. Un caso curioso en las aulas universitarias ${ }^{195}$ lo muestran los docentes que enseñan literatura y análisis crítico del discurso. Son como dice el adagio popular: predican pero no aplican. Los docentes de literatura carecen de sencillez, sensibilidad y humanismo. Los de análisis del discurso son los más intransigentes, antidemocráticos y cerrados de los maestros. ¿Por qué? ...

Un profesor debe situarse, como tal, como profesional de la educación, en un contexto propio de sensibilidad y comprensión de su entorno para comprobar cuáles son los elementos que afectan a sus posibles interlocutores, los estudiantes. Estos últimos pertenecen al mismo molde cultural. $Y$ no interesa que los profesores hayan hecho un posgrado en el exterior. Se vive la realidad, se vive Colombia. Es lo que basta. En ese orden de ideas creemos que los planes de estudio, los estándares, los lineamientos y cualquier tipo de documento que indique directrices para la enseñanza no necesita modificarse. En teoria, en el papel están bien, son adecuados. El cambio está en los profesores y en los alumnos que los interpretan, los viven, y discuten sobre ellos. Esos planes y documentos, esos currículos 
son la excusa para dialogar y generar saber. Lo pedagógico es proponer el diálogo, es crear las condiciones que más allá de una escuela de pensamiento o una teoría rimbombante, genere aprendizaje, genere gusto, placer y curiosidad. Citamos a nuestro maestro Rafael Flórez (1994, XVI):

Pero el futuro no existe todavía. Es una construcción abierta que abarca la totalidad de lo que hacemos y proyectamos desde hoy. No obstante el compromiso de la enseñanza es precisamente descubrir y aprender del futuro para determinar el presente. Lamentablemente, lo que está pasando en la realidad de nuestras escuelas y maestros es bien diferente. Aunque tal vez ninguno de nosotros pueda dejar de recordar la figura de aquel maestro excepcional que en algún momento de nuestra vida nos abriera un horizonte, asombrara nuestra ingenuidad o nos colocara en una perspectiva reestructuradora del mundo, la verdad es que nuestras mentes fueron "subalimentadas" en su paso por la escuela básica, por las limitaciones intelectuales de algunos de los maestros, y probablemente la misma suerte corren hoy la mayoría de los niños. Limitaciones, por supuesto, originadas no en insuficiencias cerebrales, sino en el desuso persistente de las funciones intelectivas superiores en la actividad pedagógica del maestro.

Esta cita nos permite apreciar que hay inconvenientes serios pero que es posible solucionar y cambiar. Invitamos al diálogo interdisciplinar. No más bandos que abren y cultivan trincheras en donde se camuflan y protegen los soldados de la literatura y la lingüística, esperando que los pedagogos y didactas negocien los términos de una guerra impune. Creemos que el currículo es un dispositivo ecléctico e integral que puede echarse a andar con el fin de lograr una comprensión humanizadora del mundo que nos rodea. Es una educación para la paz y la vida. Un plan de estudios es una caja de herramientas conceptuales que nos permiten construir una imagen del mundo; imagen clara, justa y feliz.

\section{Hacia donde mirar}

Creemos que siempre hay un norte cuando hemos decidido seguir un camino. Si el profesor, el practicante, el estudiante, los padres, la comunidad en general quieren comprender lo que es la educación y el conocimiento, deben comprender primeramente lo humano. Sin este rasgo, sin la adecuada mirada, todo intento curricular es nulo, es estéril. Por eso como conclusión de este ensayo invitamos a mirar propuestas humanas como la de Edgar Morin, hacia allá debemos mirar:

\section{Enseñar la condición humana \\ El ser humano es a la vez físico, biológico, síquico, cultural, social, histórico. Es esta unidad compleja de la naturaleza humana la que está completamente desintegrada en la educación a través de las disciplinas y que imposibilita aprender lo que significa ser humano. Hay que restaurarla}

\footnotetext{
${ }^{195}$ No son impresiones nuestras sino que son las mismas impresiones que compartimos con compañeros de otras universidades que estudian español y literatura. Sin embargo insistimos en que NO son todos los profesores hay muchos que son buenos y transmiten en su cátedra el amor por la literatura y por el cuestionamiento discursivo. Queremos destacar lo negativo porque al fin de cuentas es lo más se nota y lo que más padecemos.
} 
de tal manera que cada uno desde donde esté tome conocimiento y conciencia al mismo tiempo de su identidad compleja y de su identidad común a todos los demás humanos. Así, la condición humana debería ser objeto esencial de cualquier educación (...) se indica cómo a partir de las disciplinas actuales, es posible reconocer la unidad y la complejidad humanas reuniendo y organizando conocimientos dispersos en las ciencias de la naturaleza, en las ciencias humanas, la literatura y la filosofía y mostrar la unión indisoluble entre la unidad y la diversidad de todo lo que es humano.

Esperamos que entre nuestros lectores se encuentren practicantes y alumnos cuyo elemento que los identifica hoy es el aburrimiento y la confusión. Si de veras están interesados los invitamos a que nos escriban $y$ formulemos un verdadero currículo desde nuestra práctica pedagógica llamado integración.

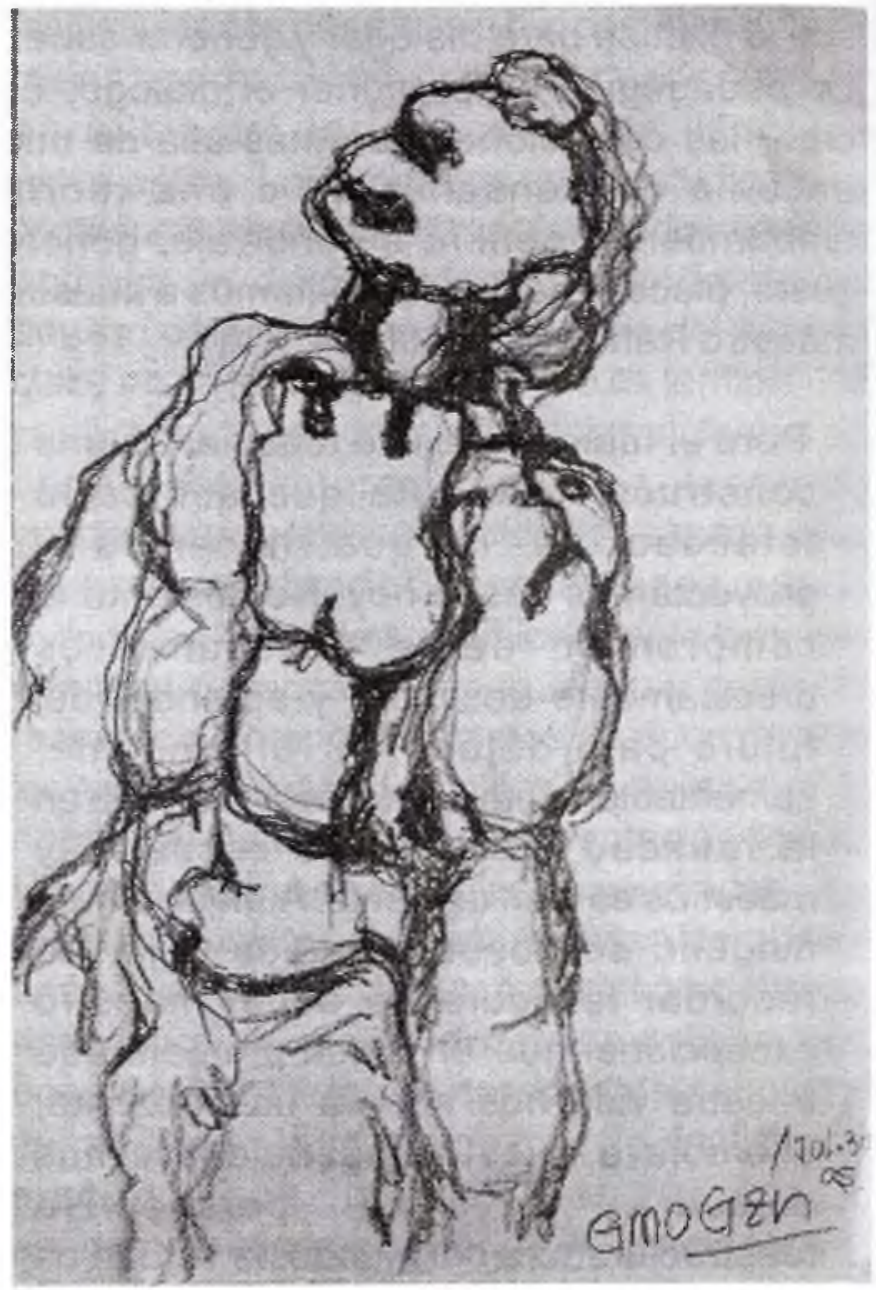

Desde los paisajes pedagógicos de Colombia, marzo de 2012 